\title{
Para leer a Terán. Revisitando Nuestros años sesentas desde una perspectiva bajtiniana
}

\author{
To read Terán. \\ Revisiting Our sixties years from a Bakhtinian perspective
}

Juan M. Testa*

\begin{abstract}
Resumen: La siguiente comunicación propone una re-lectura del clásico libro de Oscar Terán: "Nuestros años sesentas", desde una posición Bajtiniana, entendiendo este texto como un enunciado que forma parte de una cadena dialógica mayor. Partiendo desde esta posición, lo tomamos como centro, recomponemos las cadenas que lo anteceden y lo ligamos con posiciones posteriores que sostienen la misma lógica. Para ello, analizamos los elementos contextuales y paratextuales de "Nuestros años sesentas"; siguiendo lo propuesto por Ginzburg en el paradigma indiciario, buscamos indicios en el texto y los relacionamos con intervenciones pretéritas de Terán en revistas político-culturales o posiciones en debates que tuvieron lugar en esas mismas publicaciones, sin la necesaria participación de este autor.
\end{abstract}

Palabras clave: Oscar Terán, Marxismo, Historiografía, Intelectuales de izquierda, Cadena dialógica, Paradigma indiciario

\begin{abstract}
The following communication proposes a reinterpretation of the classic book by Oscar Teran: "Our sixties years" from a position Bakhtinian, understanding this text as a statement that is part of a larger chain dialogic. Starting from this position, we took as a center, recompose the chains that bind ourselves with preceding and subsequent positions held by the same logic. We analized the elements contextuales and paratextuales of "Our years sesentas"; following the proposed for Ginzburg in the paradigm indiciario, we look for indications in the text and relate them to past interventions of Teran in political-cultural magazines or positions in debates that took place in the same publications, without the necessary participation of this author.
\end{abstract}

\footnotetext{
* Argentino. Licenciado en Historia por la Universidad Nacional de Río Cuarto. Doctorando en Historia por la Universidad Nacional de Córdoba. Becario Doctoral del Consejo Nacional de Investigaciones Científicas y Técnicas (CONICET) con lugar de trabajo en la Universidad Nacional de Río Cuarto. El texto que presentamos a continuación está enmarcado en las investigaciones relacionadas al proyecto de beca doctoral, por lo tanto de allí proviene su financiamiento. E-mail. juan_testa7@yahoo.com.ar
} 
Keywords: Oscar Terán, Marxism, Historiography, Leftist intellectuals, Dialogic chain, Paradigm indiciario

Recibido: 20 enero 2016

Aprobado: 3 junio 2016

\section{Introducción}

Toda reflexión, aunque se precie de mínima, parte de un estado de inconformidad con respecto a un estado de cosas. Nuestra incomodidad historiográfica se centra en las reiteradas lecturas sobre "Nuestros años sesentas" que han canonizado un texto expresando sus potencias descriptivas sin prestar demasiada atención a su condición dialógica, en sentido Bajtiniano ${ }^{1}$, y su ubicación en una cadena de enunciados determinada.

El mencionado texto se ha convertido -tal vez sin esta proyección por parte de su autor- en un "clásico" de la historiografía argentina sobre los intelectuales y los años sesenta. Esta situación provoca la recurrente aparición de expresiones que remiten a su título o a la innovadora periodización -los sesentas como ese período que transcurre entre 1956 y 1966-. En esa clave de análisis se encuentran los estudios de Pablo Ponza ${ }^{2}$ específicamente. También pueden leerse interpretaciones como la de Sebastian Carassai ${ }^{3}$, quien se aproxima muy superficialmente a la argumentación de Terán para describir algunos sentidos de sus afirmaciones en un breve texto publicado en la Revista Prismas. Igualmente pueden rastrearse reminiscencias de Nuestros años sesentas en artículos de Hugo Vezzetti ${ }^{4}$, entre otros.

El lector tiene la opción también de acceder a tres dossier específicos sobre Oscar Terán, uno de ellos publicados en la Revista Quinto Sol ${ }^{5}$ dedicado a la

\footnotetext{
${ }^{1}$ Mijail Bajtin, Estética de la creación verbal, Buenos Aires, Siglo XXI Editores. 1998

2 Pablo, Ponza Intelectuales y violencia política 1955-1973. Historia intelectual, discursos políticos y concepciones de la lucha armada en la Argentina de los 60-70, Córdoba, Babel Editorial, 2010. Pablo, Ponza "Los sesenta-setenta: intelectuales, revolución, libros e ideas", Revista Escuela de Historia. $\mathrm{N}^{\circ}$ 6, Salta, ene-dic 2007, 137-160

3 Sebastian,Carassai, "El malestar Terán: El factum como fatum. A propósito de Nuestros años sesentas", Prismas. Revista de Historia Intelectual, N 19, 2015, 207-213

${ }^{4}$ Hugo, Vezzetti, "Los sesenta y los setenta. La historia, la conciencia histórica y lo impensable". Prismas. Revista de Historia Intelectual, No 15, 2011, 53-62

${ }^{5}$ AA.VV., "Aportes y debates sobre la reedición del libro de Oscar Terán: Nuestros Años Sesentas. La formación de la nueva izquierda intelectual", Revista Quinto Sol, Vol. 17, N² 2, diciembre de $2013,1-16$
} 
reedición del texto que analizaremos, el segundo en la Revista Prismas ${ }^{6}$ a propósito de la muerte de este autor y el tercero en la Revista El Río Sin Orillas ${ }^{7}$.

Este estado del arte representa solo una vía de la lectura centrada en el autor y su obra, o en las influencias que ese texto puede haber ocasionado en la historiografía que le sucede. El mismo sirve para otorgar una grilla de investigaciones que pueden ser consultadas pero no tienen influencia analítica en nuestro trabajo.

Podemos reconstruir otro estado del arte con estudios que se dedican al período que genéricamente se denomina "crisis del marxismo", como los de Elías Palti $^{8}$ y Julia Exposito ${ }^{9}$, entre otros.

Nuestra propuesta, sin desconocer los textos precedentes y contemporáneos, busca desprenderse de esos enfoques pretendiendo avanzar desde lo contextual, desde los elementos paratextuales, el diagrama de la publicación, y las participaciones que Oscar Terán realizó previamente a la primera edición de Nuestros años sesentas en revistas político-culturales.

Hay tres nociones que debemos clarificar ya que son centrales en nuestra argumentación: contexto, cadena dialógica e indicios. En la compleja relación de las mismas depende la se sustenta la matriz de comprensión aplicada.

Cuando hablamos de cadenas dialógicas, estamos pensando en actuaciones discursivas -generalmente impresas- pasadas, que intervienen en una discusión, una trama dialogal de mayor escala.

Esta perspectiva se sostiene en las propuestas de Bajtin, quien argumenta que en mayor o menor medida todo hablante de por sí es un contestatario, no un primer hablante sino que cuenta con la presencia de enunciados que lo preceden, sean estos suyos o ajenos, con los cuales su intervención se relaciona, se encadena. Sostiene Bajtin:

“Cada enunciado está lleno de ecos y reflejos de otros enunciados con los cuales se relaciona por la comunidad de esfera de la comunicación discursiva. Todo enunciado debe ser analizado, desde un principio, como respuesta a los enunciados anteriores de una esfera dada de la comunicación discursiva, en un problema,

\footnotetext{
${ }^{6}$ AA.VV., “Un camino intelectual: Oscar Terán, 1938-2008”. Prismas. Revista de Historia intelectual, $\mathrm{N}^{\circ} 12,2008,191-210$

7 AA.VV., "Lecciones de un moderno intenso", Revista El Río Sin Orillas, Año 2, N², Octubre de 2008, 320-345

${ }^{8}$ Elías José, Palti, Verdades y saberes del marxismo. Reacciones de una tradición política ante su "crisis". Buenos Aires, Fondo de Cultura Económica, 2010

${ }_{9}$ Julia, Exposito, "La crisis del marxismo en una perspectiva latinoamericana. Diálogo entre el morenismo y los estudios subalternos", Revista Izquierdas, 24, julio 2015, IDEA-USACH, 108-126
} 
en un asunto, etc. Uno no puede determinar su propia postura sin correlacionarla con las de otros. Por eso cada enunciado está lleno de reacciones -respuesta de toda clase dirigidas hacia otros enunciados de la esfera determinada de la comunicación discursiva. ${ }^{10 \prime}$

Un enunciado al ser siempre relacional y determinado por su contexto, remite internamente a otras voces, principalmente pretéritas y se convierte en un eslabón más en una cadena de diálogos que tiende a sostenerse en el futuro. A su vez, por contexto entenderemos: la delimitación de los bordes de la cadena dialógica, sus condiciones, externas e internas de posibilidades.

Entenderemos por indicios a las huellas indelebles en los textos que expresan marcas profundas no sólo de la identidad autoral sino también del contexto en el que están insertos en tanto enunciados.

Otra de las aspiraciones, aunque un tanto pretenciosa, es seguir un estilo conjetural e indiciario, como propone Carlo Ginzburg11, en efecto, recomponer un objeto determinado -avanzando desde las conjeturas- a partir de las huellas que puedan rastrearse en fragmentos, sean estos documentales, textuales, pictóricos, entre otros.

Cabe mencionar que sin desconocer el recorrido autoral de Terán, la selección documental sólo se centra en las participaciones ya que consideramos que siguiendo estos artículos, puede verse con mayor claridad la discusión político-intelectual de la que forma parte el texto.

Este corpus documental determinado está compuesto por intervenciones de Oscar Terán en revistas político-culturales de fines de las décadas del setenta y ochenta ya que, las mismas nos otorgan la posibilidad de recomponer los distintos climas de un debate. Las revistas, como sostiene Martina Garategaray, pueden ser definidas como laboratorio de ideas, ámbitos de sociabilidad, soporte de itinerarios personales, lugares relevantes de legitimación política y cultural12. Además de las intervenciones mencionadas, utilizaremos contribuciones de otros autores que se encuentran relacionadas $\mathrm{y}$, a su vez, aparecieron en esos mismos espacios.

Los indicios que podemos identificar en los otros autores nos permiten reconocer lo que para Bajtin va a llamarse polifonía o en Kristeva intertextualidad.

\footnotetext{
${ }^{10}$ Mijail Bajtín, Estética de la creación verbal, Buenos Aires, Siglo XXI Editores, 1998, 281

${ }_{11}$ Carlo Ginzburg, Mitos, emblemas e indicios, Rosario, Prometeo, 2012

12 Martina Garategaray, "Democracia, intelectuales y política. Punto de Vista, Unidos y la Ciudad Futura en la transición política e ideológica de la década de los '80", Estudios, № 29, 2013, 54.
} 
La metodología de trabajo fue la siguiente: tomamos "Nuestros años sesentas" como centro y desde allí exploramos artículos escritos por Oscar Terán en revistas. Con el mismo criterio exploratorio, rescatamos algunos artículos posteriores a la primera edición del libro.

La propuesta de reconstrucción que pensamos, se relaciona con la siguiente hipótesis: Nuestros años sesentas es un eslabón en una cadena dialógica determinada que puede rastrearse en evidencias textuales desde algunos años antes de su publicación y que se mantiene hasta nuestros días, convirtiéndose así nuestro propio trabajo en otra estación más de ese encadenamiento.

La construcción de la argumentación tiene un diseño para que nuestras afirmaciones tengan correlato con las evidencias documentales, que a su vez se muestre un recorrido de lecturas posibles que parte desde el acercamiento a Nuestros años sesentas, reconstruye una cadena dialógica centrándose en la dimensión diacrónica pretérita y arriba a algunas reflexiones finales.

\section{Terán y sus advertencias}

Al percibir el título completo del texto de Oscar Terán en cuestión, podemos leer que Nuestros años sesentas se encuentra acompañado por un subtítulo que sugiere más de lo que dice: La formación de la nueva izquierda intelectual argentina. Además de este dato, en el afán por revisar algunos elementos contingentes del texto, podemos observar con nitidez -porque se encuentra sobre un fondo blanco y escrito en mayúscula de manera diferente en la portada de la edición de 2013- la inscripción "edición definitiva", carácter que seguramente se deba a la inclusión de un estudio preliminar realizado por Hugo Vezzetti y un apéndice que agrega a la edición la conversación entre Oscar Terán y Silvia Sigal que fue publicada en la Revista Puntos de Vista en 1992.

¿Porque nos detenemos en estos dos elementos? De algún modo porque estamos frente a elementos que nos definen condiciones en cuanto a la lectura del texto.

Con respecto al subtítulo, queremos poner el énfasis en la concepción de "formación" que se expresa allí.

De alguna manera, aunque no figure como referencia bibliográfica en el texto, podemos ver una alusión, tal vez elíptica, al libro de E.P. Thompson $L a$ formación de la clase obrera en Inglaterra del año 1963, traducido al español en 1989 por la editorial Crítica.

Hay en el texto de Terán, o en la concepción del mismo, una utilización similar de "formación" a la del libro de Thompson, quien señala en el prefacio a la 
primera edición, escrito en 1962: formación porque es un proceso activo que debe tanto a la acción como al condicionamiento ${ }^{13}$.

Mientras que al segundo elemento, la "edición definitiva", le otorgamos el peso de una operación editorial que si bien es entendible en el contexto de la edición en tanto industria cultual, nos alerta de que por el momento no pueden incorporarse a la misma otras lecturas, que este es el formato, de alguna manera, final.

Pero debemos volver a la expresión de Thompson y buscar las acciones y los condicionamientos en esa formación que puede leerse en Nuestros años sesenta. Para ello, nos remitiremos al texto en sí, a las "advertencias", el primer capítulo del libro que no se presenta como un prefacio, ni expresa ese acto de habla anterior o previo a un texto, sino que advierte al lector de la existencia de un estado motivacional puntual y de una práctica de escritura determinada por ese estado.

En las primeras páginas Terán advierte, y es conveniente tomar este párrafo textualmente, a pesar de su extensión:

"En los capítulos que siguen se trata, en suma, de unos actores intelectuales constituidos por una coyuntura histórica14, por una colocación institucional y social, y por una discursividad. Si este último aspecto ha resultado privilegiado, se debe en parte a que esta indagación decidió destacar este sesgo desde el orden de las razones, y no por suponer que semejante perspectiva coincida únivocamente con su jerarquía de determinación en el orden de lo real. empero, no pocas veces me ha sorprendido la ambigua sensación de estar en rigor observando más bien a un conjunto de ideas que se apoderaron de unos hombres $y$, al hacerlos creer lo que creyeron, los hicieron ser lo que fueron". 15

Vemos en este párrafo la expresión de una tensión entre acción y condicionamientos que trataremos de profundizar. Sobre la noción de acción no hay un margen demasiado amplio para la reflexión en el sentido que el párrafo la supone: los hicieron ser los que fueron. En cuanto a los condicionamientos podemos avanzar en algunas líneas.

Podemos encontrar al menos tres condicionamientos posibles, uno propio de quien escribe, de su contexto de escritura, que trataremos en el próximo acápite.

\footnotetext{
${ }^{13}$ Edward P. Thompson, "Prefacio", Edward P. Thompson, Obra Esencial, Barcelona, Crítica, 2002, 13.

${ }^{14} \mathrm{El}$ resaltado es nuestro

15 Oscar Terán, Nuestros años sesentas. La formación de la nueva izquierda intelectual argentina, Buenos Aires, Siglo XXI Editores, 2013, 45.
} 
Los otros dos, ligados al texto y a una distinción histórica incluida dentro de una tradición de pensamiento, el marxismo.

Cuando Terán objetiviza su "ambigua sensación" al percibir que un conjunto de ideas se apoderaron de unos hombres, está volviéndose sobre la tradición teórico-crítica, porque aunque en estaciones posteriores busque ligar tal formulación con aquella de los primeros párrafos del XVIII Brumario de Luis Bonaparte: "Los hombres hacen su propia historia, pero no la hacen a su libre arbitrio, bajo circunstancias elegidos por ellos mismos, sino bajo aquellas circunstancias con que se encuentran directamente, que existen y les han sido legadas por el pasado"16. Las circunstancias para Marx o los condicionamientos en Thompson, sin ser conceptualmente idénticos cumplen una función de fuerza opuesta a la acción, sea esta individual o colectiva. Esta concepción no es la misma en el Terán de Nuestros años sesentas, quien sujeta la acción a la circunstancia, ya que es esta la que le otorga sentido, no actuando como fuerza opuesta, sino como un conjunto de creencias y valores capaces de organizar mundos de una notable densidad ${ }^{17}$, con la potencialidad de hacer actuar a los sujetos de determinada manera.

Hay claramente aquí un proceso de alejamiento de una concepción materialista de la historia, porque la tensión entre acción y condicionamientos, lo que es lo mismo a la relación entre sujeto y contexto no sólo se determina por el contexto sino que se determina fatalmente por un contexto de creencias y valores, o simplemente de ideas concebidas como "pasiones ideológicas".

Este punto en sí, podría llevarnos varias páginas de reflexión, que no realizaremos aquí porque sería alejarnos de nuestros objetivos.

Pero, ¿qué intención tiene llegar hasta aquí, o leer un texto desde aquí, o sea sin leerlo internamente?

Tiene múltiples intenciones, pero la primordial es realizar algo poco novedoso que es comprender un texto en su contexto, tomando este último como la cadena de enunciados que lo preceden y que se derivan de allí.

Entonces comenzamos a hilvanar el próximo acápite centrado en un trabajo de recomposición de esa cadena de enunciados con el fin de lograr comprender el proceso de cambio de un intelectual de izquierda, a la luz de sus debates y diálogos, y como sus modificaciones afectaron su escritura. Porque, y aquí pronunciamos una de nuestras conjeturas: Nuestros años sesentas, no sólo manifiesta internamente la tensión entre acción y condicionamientos sino que también la expresa externamente, ya que se coloca entre la historia y la memoria, y a partir de la problematización de sus márgenes podemos comprender el estado de discusión previo y una reformulación de un perfil intelectual personal y a la vez

\footnotetext{
${ }^{16}$ Karl Marx, El XVIII Brumario de Luis Bonaparte, Madrid, Fundación Federico Engels, 2003, 13.

17 Terán, op. cit., 45-46
} 
generacional. En efecto, como responde E. P. Thompson en una entrevista que puede leerse en Tradición, revuelta y consciencia de clase, cuando le consultan por las motivaciones que lo llevaron a escribir "La Formación de la clase obrera en Inglaterra": Las reflexiones que median entre una obra artística o intelectual, nunca son una y la misma18.

Esos márgenes son expresados con claridad en el capítulo "Final" del libro. Del que podemos rescatar dos párrafos o parte de ellos, con el fin de dar conclusión a esta primera parte. Sostiene Terán:

"En rigor, las páginas que acaban de leerse han tratado probablemente en vano de mantener una distancia pudorosa con acontecimientos y discursos constitutivos de mi propio perfil no sólo intelectual.", además agrega, "entre el homenaje y el exorcismo, varias veces a lo largo de los últimos años retom[é] y abandon[é] este ensayo (...) porque en el entramado de su construcción me resultaba difícil distinguir lo que formaba parte de mis propias pasiones respecto de aquello que -se supone- debía ser la resultante más descarnada de mi oficio intelectual" ${ }^{19}$

Cabe concluir este apartado con una reflexión de Marx, que hace referencia de cierto modo, a la reconstitución de una subjetividad "destruida" por los efectos de las derrotas revolucionarias. Señala Marx: "La tradición de todas las generaciones muertas oprime como una pesadilla el cerebro de los vivos. Y cuando éstos aparentan dedicarse precisamente a transformarse y a transformar las cosas, a crear algo nunca visto, en estas épocas de crisis revolucionaria es precisamente cuando conjuran temerosos en su auxilio los espíritus del pasado..."20

Aquí volvemos a la idea de condicionamientos de Thompson, para sugerir que "la experiencia de la derrota revolucionaria" 21 condiciona fuertemente el texto

${ }^{18}$ Edward P. Thompson, Tradición, revuelta y consciencia de clases. Estudios sobre la crisis de la sociedad preindustrial, Barcelona, Editorial Crítica, 1984, 295.

19 Terán, op. cit., 245.

${ }^{20}$ Marx, op.cit., 13.

${ }^{21}$ Por "experiencia de la derrota revolucionaria" estamos refiriéndonos a diferentes situaciones y procesos que se encuentran ligados al período 1973-1976, en el que se profundiza la conflictividad entre organizaciones armadas y el Estado Argentino, fundamentalmente con la organización, efectivización y cesión de poder al Lopezreguismo dentro de la triple A (Alianza Anticomunista Argentina), como así también en el Operativo Independencia desarrollado en Tucumán.

Por otro lado, la expresión señala un período dentro de una cronología de la crisis del marxismo. Para ello puede consultarse: Omar, Acha y Débora, D’antonio, "Cartografía y perspectivas del marxismo latinoamericano", A contracorriente. Una revista de historia social y literatura latinoamericana, NC. StateUniversity, Vol. 7. N 1. Winter 2010, 210-256 
de Terán y uno de los momentos determinantes de su contexto de enunciación, es decir, hay un hilo rojo entre 1976 y 1991, así como de 1991 con 1955, que trasciende el texto y que podremos comprender mejor en el próximo acápite.

\section{Cadenas}

Existe, y de cierto modo se torna imposible no explicitarlo, la tentación metafísica por la búsqueda de los orígenes, de hallar el o los acontecimientos en el que se desata una cadena causal. Pero reconocemos también, como lo hemos hecho en la introducción de este artículo, que por más que tengamos evidencias para sostener que algunos acontecimientos, especialmente aquellos que podemos analizar desde la perspectiva de los enunciados, se remontan específicamente a un momento. Está claro que el mito de los orígenes no ha sido plenamente resuelto en la práctica del oficio del historiador, ya que de alguna manera logra filtrarse entre nuestros postulados dejando entrever sus huellas.

Este tramo del texto, pretendiendo evitar esa tendencia, se sostiene teóricamente en Bajtin, en sus ideas de enunciado, dialogicidad y polifonía ${ }^{22}$. Retomamos la idea que veniamos sosteniendo desde los primeros párrafos: Nuestros años sesentas es un eslabón en una cadena dialógica determinada que puede rastrearse en evidencias textuales desde algunos años antes de su publicación y que se mantiene hasta nuestros días, convirtiéndose así nuestro propio trabajo en otra estación más de ese encadenamiento.

Procedimentalmente centrar nuestra mirada en la cadena de diálogos no debe hacernos perder de vista el contexto, ahora entendido como condiciones, externas e internas de posibilidades para una enunciación determinada.

Un artículo de Emilio De Ípola publicado en la revista Puntos de Vista en el año 1997, va articular de alguna manera, las directrices de un debate que para el momento en el que escribe eso, está bastante resuelto, pero que logra representar en toda su significatividad.

También utilizamos esta expresión para identificar el proceso de construcción y denominación de la experiencia por parte de los intelectuales exiliados. En Controversia puede encontrarse recurrentemente esta apreciación.

22 Pueden ampliarse estas concepciones en: Valentin Voloshinov, El marxismo y la filosofía del lenguaje, Madrid, Alianza Editorial, 1992. Y, Mijail Bajtín, Estética de la creación verbal, Buenos Aires, Siglo XXI Editores, 1998, 281-284. 
De Ípola encuentra que los años ochenta fueron epicentro de un conjunto de cuestionamos que de forma fragmentaria y a los efectos prácticos insuficiente, se volvieron sobre el discurso heroico y eufórico de los sesenta y más aún su "traducción práctica" en los setenta ${ }^{23}$.

La intervención relata y problematiza una escena en el patio de la Facultad de Ciencias Sociales en la Universidad de Buenos Aires, mientras De Ípola se dirigía hacia el aula que tenía asignada para dar clases. La narración se asienta sobre una triangulación entre: cruzar el patio, observar los carteles de las agrupaciones estudiantiles y volverse sobre una experiencia generacional y unos debates específicos. Esta particular construcción convierte a este artículo en una estación interesante desde la que podemos comenzar a rastrear las huellas de esta cadena dialógica.

En el artículo recuerda el carácter desgarrador que tuvo para unos pocos ese proceso de cuestionamientos que tuvo lugar en los ochenta, mientras que para la mayoría -en la que se incluye- esa revisión fue una suerte de expediente indoloro aunque no exento de altibajos, contramarchas y confrontaciones a veces ásperas, que condujo al despojo de algunas creencias que, en distintos niveles, habian sido fervorosamente las nuestras ${ }^{24}$. (25)

De Ípola sostiene que se trató de "un conjunto encadenado y complejo de movimientos críticos que afectó a núcleos fuertes de significaciones culturales y políticas" 25 . (26)

Esta afirmación nos permite ver lo complejo de nuestra propuesta de análisis. En efecto, Nuestros años sesentas es una estación en una cadena discursiva que está integrada por intervenciones realizadas en un tiempo determinado -que genéricamente podemos llamar los ochenta- por los mismos sujetos que según Nuestros años sesentas son construidos por una conjunto de creencias, valores e ideas que los hicieron ser lo que fueron y, que al momento de intervenir en esa cadena buscan, si no despojarse de ese acervo, por lo menos limitar su influencia.

Esos ochentas - para utilizar la estilística de Terán cuando pluraliza los sesentas, demasiado genéricos, conforman el contexto de enunciación. Son los que, construyen y se sostienen en la experiencia de la derrota, la situación de exilio, la puesta en crisis teórica-práctica y política del marxismo y el acercamiento a una posición social-demócrata de un conjunto de intelectuales que se habían identificado con la izquierda revolucionaria. Cabe preguntarse entonces: ¿De quiénes fueron "nuestros" años ochentas?

\footnotetext{
${ }^{23}$ Emilio De Ípola, "Un Legado Trunco", Punto de Vista. Revista de Cultura, Año XX, N 58, Agosto de 1997, 25-27.

24 Ibid., 25.

${ }^{25}$ Ibid., 26.
} 
La pregunta, que responde casi literalmente a la primer advertencia de Terán en el texto que estamos analizando se transforma, desde unos años a esta parte como objeto de reflexión histórica e historiográfica. En esta línea podemos encontrar estudios de Martina Garategaray, Marcelo Starcembaum, Jimena Montaña ${ }^{26}$, entre otros investigadores que recomponen dicho proceso.

Estos ochentas, son nuestros ochentas porque así denominamos al contexto de enunciación de esa cadena que nos precede y de la que formamos parte, y no sólo por eso, sino porque sólo a condición de reconocer su trascendencia podemos objetivar sus huellas en nuestro pensamiento.

Estos largos ochentas, podemos rastrearlos desde 1979 en la intervención de Aricó en el primer número de Controversia, en 1985 en un artículo de Beatriz Sarlo y también podemos ver sus marcas en las expresiones de De Ípola en 1997 y en las de Oscar Terán en el quinto número de la revista Lucha Armada del año 2006.

Es decir, esos ochentas, también son nuestros, porque no se limitan a la clásica división en décadas, ni responden a esa estructurada división del tiempo. Son nuestros, porque en definitiva son la marca de la derrota corporizada en debates, en prácticas intelectuales y en composición de formas intelectuales que más se asocian con la comunidad científica Habermasiana, que con las nociones de compromiso y revolución previa.

\section{II}

Presentaremos a continuación una serie de intervenciones -las mismas que De Ípola caracterizó de fragmentarias- que hemos podido rastrear siguiendo las huellas de la expresión de Oscar Terán en las "advertencias". Siguiendo esos hilos, intentaremos reconstruir las instancias previas de un estado de debate que podemos encontrar explicitado en Nuestros años sesentas.

En su mayoría, estos debates tienen su centro en dos revistas: Controversia ${ }^{27}$ y Punto de Vista, las que, de algún modo, nuclearon a intelectuales que luego de sostener en el tiempo sus afinidades electivas a través de la participaciones

${ }_{26}$ Pueden consultarse: Garategaray, op.cit., 53-72; Marcelo Starcembaum, “Historia, política y responsabilidad: Óscar Terán y la autocrítica entre los intelectuales de izquierda en Argentina", Historia de las ideas, estudios de la memoria, $N^{\circ}$ 51-52, Enero-junio/ Julio-diciembre de 2012, 143170; Jimena Montaña, "Consideraciones en torno a la metamorfosis del intelectual latinoamericano en los años noventa", Questión. Revista especializada en Periodismo y Comunicación, Vol. 1, N 40, Octubre-diciembre 2013, 127-141.

${ }^{27}$ Es una publicación de los exiliados argentinos en México dirigida por Jorge Tula que nuclea a la mesa peronista y la mesa socialista. Su consejo editorial está conformado en la mayor parte de su recorrido por: José Aricó, Sergio Bufano, Rubén Sergio Caletti, Nicolás Casullo, Ricardo Nudelman, Juan Carlos Portantiero, Héctor Schmucler y Oscar Terán. En el número siete se incorpora Carlos Abalo. 
constantes en espacios de producción y sociabilidad, componen, lo que podemos designar como familia intelectual.

La selección de los artículos tuvo pretensiones de exhaustividad pero, no por eso, deja de ser una selección y tiene su grado de arbitrariedad implícito.

Los ochentas, en el sentido que lo estamos utilizando, se expresan con claridad a partir del primer número de la revista Controversia, en la que, José Aricó presenta un artículo con el título "La crisis del marxismo". Esto desata un debate que se continúa en los números siguientes de dicha publicación.

Aricó se pregunta si no habrá llegado la hora de una reflexión del marxismo. Esta profunda interpelación expresa no sólo un estado de malestar sino una agenda futura.

Conviene aquí soportar la carga de un texto que recurra ampliamente a las citas que utilizar un sistema de parafraseo que tal vez obture las interpretaciones.

Aricó se pregunta: “ ¿No es hora ya de que los marxistas acepten los riesgos de una polémica que se les impone más allá de sus recatadas perplejidades o de sus obtusas resistencias? ¿No ha llegado el momento de comenzar a deshacer un enredo que amenaza conducir a una situación sin salida?" 28.

Esta pregunta, contiene en sí misma una respuesta, y otra pregunta que podrá verse a lo largo de las próximas intervenciones. ¿Puede llamase socialistas a las sociedades surgidas de la aparente destrucción del capitalismo? ${ }^{29}$

La presentación de Aricó antecede un artículo de Paramio y Reverte titulado: Razones para una contraofensiva. En esta intervención, los autores plantean que el marxismo se encuentra en crisis, pero la misma es de carácter teórico y ha sido temporalmente aplazada. Que el marxismo en crisis es aquel con el que siempre relacionamos, de manera restrictiva, el término, es decir: el marxismo revolucionario, mientras que el reformista se encuentra en un gran momento. Atribuye algunas causas, aunque no determinantes, a una crisis mayor de la cultura y los valores occidentales que afectan también al marxismo. Sostienen que: "esta crisis tiene un doble origen: de una parte, la refutación histórica de algunas de las tesis que en su momento definieron a este marxismo revolucionario frente al reformista; de otra, la desvalorización ideológica de las sociedades y organizaciones que llegaron a identificarse con ese marxismo revolucionario ${ }^{30}$. Además, esta crisis del marxismo expresaría la perdida de potencialidad

\footnotetext{
${ }^{28}$ José Aricó, "Crisis del marxismo. Presentación", Controversia, Año I, Nº 1, 1979, 13.

${ }^{29}$ Idem., 13.

${ }^{30}$ Ludolfo Paramio. y Jorge Reverte, "Razones para una contraofensiva", Controversia, Año I, N 1, 1979, 14.
} 
movilizadora del pensamiento marxista y su imposibilidad para ofrecer visiones verosímiles (y deseables) del futuro". 31

En el número dos-tres de Controversia, Oscar del Barco responde a este artículo señalando, en primer lugar, que al otorgar el carácter de teórica a la crisis del marxismo, se corre el riesgo de esfumar su raíz fundamentalmente política ${ }^{32}$.

Para polemizar con la caracterización teórica que Paramio y Reverte realizan de la crisis, Del Barco retoma la escisión entre teoría y praxis, y argumenta que la reconversión del marxismo en una teoría constituye una de las causas de la crisis. Desde allí cimenta su posición en este debate que luego profundizará con siguiente afirmación:

“El marxismo, según mi criterio, no es una teoría que acompaña a la práctica, que está al servicio de la práctica, ni tampoco es un "arma" del proletariado, sino que más bien debe determinarse como formas (teóricas) de ser de las clases y sectores de clases explotadas $^{33}$, desplazándose así por lo tanto el problema del estatuto y el origen es la teoría" 34 .

Y luego continúa su razonamiento:

"Si el marxismo, como pienso, es el conjunto de formas teóricas que van adquiriendo en su proceso las prácticas revolucionarias, entonces la crisis no puede ser sino una crisis política, vale decir morfológica, y donde el acto de marcar una predominancia o un "origen" se funda en la propia práctica. Para decirlo claramente: se trata de la crisis de la II y la III Internacional, del reformismo y del bolchevismo -leninismo" 35 .

En síntesis, para Del Barco, no hay teoría por fuera de las prácticas revolucionaria, sino que este conjunto de formas teóricas que se adquieren en esas prácticas son eminentemente políticas, es por ello que sostiene que la crisis es "política", por lo tanto es la expresión de la toma de conciencia del fracaso de un tipo de práctica política ${ }^{36}$. Esta discusión no se agota en estas dos intervenciones sino que abren una cadena en la que interactúan diversos sujetos.

\footnotetext{
31 Idem., 14.

32 Oscar Del Barco, "Respuesta a Paramio y Reverte. Observaciones sobre la crisis del marxismo", Controversia, Año I, N², 1979, 12.

${ }^{33} \mathrm{El}$ resaltado es nuestro.

34 Del Barco, op.cit., 12.

35 Idem., 12.

36 Ibid., 13.
} 
En el número cinco de Controversia, Paramio y Reverte responden a Del Barco en un Crisis del marxismo. El marxismo y el minotauro. Respuesta a Oscar del $\mathrm{BarCO}^{37}$, que obtiene su contestación en el número seis de la misma revista.

En el número siete de Controversias encontramos la primera intervención de Oscar Terán en esta cadena dialógica. En el artículo De socialismos, marxismos y naciones, podemos encontrar algunas huellas que luego podrán entre-leerse en próximos textos del autor, especialmente en Nuestros años sesentas.

Esta intervención comienza con unos epígrafes centrales en la estructuración de los argumentos, el primero de ellos sobre la ronda de las madres de plaza de mayo reclamando por la suerte de sus hijos; el segundo alude a un paro de ocho mil trabajadores marítimos y, el tercero referencia la opinión benevolente de un mandatario chino sobre la presidencia de Videla.

El inicio y el final de la contribución de Terán son formidables ya que resumen toda una posición a lo largo del texto:

“... lo más evidente parece ser que, apretujados ante el doble apoyo concitado por la dictadura de parte de las dos potencias dominantes en el comunismo internacional, la historia se ha empeñado en colocar a la izquierda argentina en una situación donde la profunda relativización de parámetros exteriores se ha tornado una necesidad ineludible. Ante esta retirada de los modelos sagrados que tantas veces nos fascinaron con la fuerza con que la luna atrae a las mareas, ¿qué nos queda? ¿la patria?...38"

El final de su enunciado permite interrelacionar el comienzo con la estructuración interna, en la que de podemos notar una entonación cercana al Trotsky de la "Revolución Traicionada ${ }^{39 "}$. Terán comienza a encontrar en la derrota algunos rasgos inesperados que se sintetizan en dos epígrafes, el primero y el tercero y en la pregunta: ¿En qué antología del horror político sintetizar, sobre la misma geografía, los hechos referidos en los epígrafes que acaban de leerse?40

Continúa tejiendo su urdimbre, sosteniendo que aún si reconocemos estos "aspectos negativos del socialismo", los mismos no deben ser atribuibles a las ideas de Marx. Pero que hay cierto marxismo, que prefiere leer sacralizadamente sus textos a observar el mundo que está disolviéndose a sus pies ${ }^{41}$.

${ }^{37}$ Ludolfo Paramio y Jorge Reverte, “Crisis del marxismo. El marxismo y el minotauro. Respuesta a Oscar del Barco", Controversia, Año II, N 5, 1980.

38 Oscar Terán, “De socialismos, marxismos y naciones", Controversia, Año II, N 7, 1980, 21.

${ }^{39}$ León Trotsky, La revolución traicionada y otros escritos, Buenos Aires, CEIP León Trotsky-Museo Casa León Trotsky-IPS. 2014

${ }^{40}$ Oscar Terán, “De socialismos, marxismos y naciones”, Controversia, Año II, N 7, 1980, 20.

${ }^{41}$ Idem., 20. 
En síntesis, Terán cuestiona qué socialismo es posible imaginar, cómo efectivamente tiende a pensarse más allá de la implementación de técnicas eficaces para la consecución de la acumulación forzada dentro de un régimen de redistribución cualitativamente superior de los bienes económicos, pero que se revela incapaz de la edificación de una nueva cultura ${ }^{42}$.

Luego de esta intervención, el debate sobre la "crisis del marxismo" va perdiendo su lugar central en Controversia, que sigue reflexionando sobre el marxismo, pero corriéndose hacia el eurocomunismo, por lo menos, hasta los últimos tres números.

De esta trilogía podemos rescatar cuatro intervenciones que ligadas a esta cadena. A las dos primeras no les daremos mayor trascendencia, pero las nombramos. Las mismas se encuentran dentro de un dossier dedicado a la "democracia como problema" y corresponden a José Aricó: Ni cinismo, ni utopía ${ }^{43}$ y a Oscar Del Barco: Desde el fragor del mundo ${ }^{44}$, una carta dirigida a Jorge Tula.

Los dos textos a los que le dedicaremos nuestra atención se encuentran en los dos últimos números, el primero de ellos de Héctor Schmucler: Apuntes e interrogantes para reflexionar la política y el segundo de ellos, es de Oscar Terán y constituye una posición central en su pensamiento ya que sostiene posiciones profundas, hasta tal punto que podríamos hallar ahí uno de los puntos de quiebre en su trayectoria.

Héctor Schmucler asume que los acontecimientos de los últimos años han provocado modificaciones sustanciales en las "creencias"45 que teníamos sobre la sociedad y su transformación ${ }^{46}$. Esta posición es trascendente en nuestra estructuración porque hasta entonces el debate venía traduciendo en texto, un malestar con el marxismo, en tanto teoría y praxis, pero ahora la crisis pone al marxismo como una idea, que implica un contenido teórico y práctico seguramente, pero que es objeto de creencia. Además, aunque aquí no hayamos hecho mayor referencia, el autor concibe un nosotros explicitado, con lo cual la crisis ya no está fuera, sino que se expresa en una manifestación de esas "creencias" sobre la sociedad y su transformación por parte de un conjunto de sujetos delimitado.

Este texto es central en esta cadena, porque luego vamos a ver sus apropiaciones tanto en Terán como en Beatriz Sarlo, ya que retoma y refuerza la pregunta de Aricó que dio inicio a los debates en Controversia, genera

\footnotetext{
42 Idem., 20.

${ }^{43}$ José Aricó, "Ni cinismo ni utopía", Controversia, Año II, N 9-10, 1980.

${ }^{44}$ Oscar Del Barco, "Desde el fragor del mundo", Controversia, Año II, N 9-10, 1980.

${ }^{45}$ Las comillas son nuestras.

${ }^{46}$ Héctor Schmucler, "Apuntes e interrogantes para reflexionar sobre política", Controversia, Año III, N 11-12, 1981, 15.
} 
significantes perdurables y, porque define las condiciones para pensar el problema desde ese momento, 1981, hasta el presente.

Por ello decidimos incluir los párrafos que continúan de manera textual, sólo nos remitiremos a resaltar algunas definiciones:

"En una lectura discretamente atenta de los números de Controversia publicados hasta ahora es posible reconocer dos lenguajes que se reiteran: el de la audacia de la abstracción y el de la vejez de ciertos postulados políticos ${ }^{47}$. ¿Podríamos haber hecho otra cosa? ¿En qué medida han influido en nosotros la percepción de que lo tautológico es tranquilizante y por lo tanto se vuelve aceptable, creíble? La inquietud que genera nombrar lo que los hábitos culturales y las limitaciones ideológicas han reprimido ¿no nos ha empujado a repetir pasadas retóricas, a reandar caminos transitados, aunque a veces se cambien los decorados de los linderos? Cuánta imaginación nos hemos negado porque parece reñida con la solemnidad de las demostraciones "científicas"? ¿Cuánta realidad, en definitiva, ha pasado intocada a nuestro lado porque nuestros modelos mentales previos no ofrecían el lugar preciso para otorgarles existencia?48" (...) “Qué es el socialismo sino el "realmente existente" o la utopía donde la subjetividad de los hombres encuentra las formas de satisfacción de los deseos?" 49

Todos los eslabones que vienen después lo hacen desde esta lógica. El último artículo, el de Oscar Terán, da inicio de esta misma manera:

“... lo que está en el fondo de la cuestión no es si estos hombres de la crisis que somos nosotros pueden formular un llamado a la esperanza que nadie les reclama, sino, al menos, pueden articular una mínima comprensión de la realidad sin reiterar los viejos esquemas que produjimos $-\mathbf{y}$ nos produjeron ${ }^{50}$ en la década sublime y mentirosa de los sesenta" 51 .

${ }^{47} \mathrm{El}$ resaltado es nuestro.

48 Schmucler, op.cit., 15.

${ }^{49}$ Idem., 15.

${ }^{50} \mathrm{El}$ resaltado es nuestro.

51 Oscar Terán, "Algún marxismo, ciertas morales, otras muertes", Controversia, Año III, Nº 14, 1981, 17. 
Dicho procedimiento implica para Terán, una redefinición del marxismo, ya que la ineficaz interpretación primariamente economicista, la huidiza cuestión de la última instancia ${ }^{52}$, señala el lugar de un enigma.

La cuestión de la última instancia va a generar nuevos eslabones en esta cadena dialógica con una discusión entre Terán y Sazbón en la revista Puntos de Vista. Terán, buscando evitar el elemento totalizador dentro del marxismo propone que sea tomado como una "caja de herramientas":

"como un conjunto de instrumentos que aún pueden servir para el ejercicio de las luchas y la comprensión de lo real debería plantearse en sus límites el tema de aquella remoralización de la política de que hace pocos años hablara Habermas, tarea íntimamente vinculada con el ideal de un socialismo democrático y por ende con la descentralización de los poderes" ${ }^{\prime 5}$.

Y, nuevamente como en su intervención anterior, el final del artículo es extremadamente esclarecedor de lo que vendrá $\mathrm{y}$, es nuevamente una decisión reproducirlo casi en su totalidad:

“... quisiera preguntarme: qué valen ciertos valores, costumbres y orgullos nacionales después de La Perla y los demás campos de tortura y exterminio argentinos. Al leer los testimonios que rescatan una parte ínfima pero visceral de ese escarnio, uno se pregunta cómo se ve la Argentina desde la perspectiva de uno de esos mataderos donde toda la dignidad humana parece haberse refugiado en unos cuerpos doloridos y alucinados a los que hoy algunos sólo quieren concederlos -otra vez- el derecho a la palabra $\mathrm{o}$ al silencio- a las pobres palabras que emiten o retienen como el sentido mismo de sus vidas- si han permanecido "incólumes" ante el enigma, sin darnos cuenta de que el enemigo también éramos nosotros, es decir, nuestros propios sueños y la ignorancia de las fuerzas reales que motorizan los cambios sociales ${ }^{54}$. Es preciso, entonces, no analizar el terrorismo -ese espacio de restitución ilusoria de lo privado en el mundo de la transparencia burguesadesde el amoralismo de la política, para no recaer en esa afirmación del consejo directivo de la UOM -que otras fuerzas políticas argentinas comparten- donde, colocándola en el mismo nivel de enfrentamiento con el lopezrreguismo, se estampa -como un ayudamemorias para militares desagradecidos- que "hemos

52 Idem., 17.

${ }^{53}$ Idem., 17.

${ }^{54} \mathrm{El}$ resaltado es nuestro. 
sido principales protagonistas de la victoria sobre la subversión". ¿Cómo puede escribirse eso cuando dicha derrota implicó la muerte no sólo de utopías, sino de miles de cuerpo triturados de quienes protendieron erróneamente a construir un mundo más digno también para aquellos que hoy reclaman su porción en el festín de la victoria?55"

¿Cuántos elementos de estos debates podemos advertir en "Nuestros años sesentas"? ¿Es viable seguir leyéndolo sólo por su aporte al campo de la historiografía, es decir, por su aporte científico? Estas dos preguntas cierran la etapa en la que los diálogos se desarrollaban en Controversias.

Luego del retorno de los exiliados en México y de que los mismos se incorporaran a Punto de Vista, la cadena dialógica continúa en esa revista, de la que también rescataremos, al igual que lo hicimos hasta el momento, una serie de artículos en los que podemos hallar rastros que nos permitan afirmar el carácter de eslabón que tiene Nuestros años sesentas.

\section{III}

La cadena dialógica que venimos recomponiendo desde las intervenciones realizadas en la revista Controversia, tiene también su momento en Punto de Vista, especialmente entre 1983 y 1985, años de los que retomaremos cuatro artículos.

El primero de ellos es de Oscar Terán y se encuentra en el número diecisiete de la revista, en la que interviene en dos momentos con distintas intencionalidades. Nosotros nos ocuparemos de la segunda, una reseña sobre un libro colectivo sobre derecho jurídico del año 1982. Su contribución lleva un título sugerente que se instala como puente entre la herencia de la revista Controversia en la discusión sobre la crisis del marxismo y el inicio de una participación sostenida en otra publicación en la que intervendrán los miembros de la mesa socialista en México que integraban dicha revista.

¿Adiós a la última instancia?56 Es una participación corta que mediante una construcción textual inteligente puede sintetizar tres años de debate y comenzar a marcar una tesitura en cuanto a la revisión del marxismo. No es menor el dato de que, como señalamos anteriormente, la "huidiza última instancia" y su carácter enigmático haya funcionado a la vez como colofón y como apertura de un mismo debate.

55 Oscar Terán, “Algún marxismo, ciertas morales, otras muertes”, Controversia, Año III, Nº 14, $1981,18$.

56 Oscar Terán, “¿Adiós a la última instancia?”, Punto de Vista, Revista de Cultura, Año VI, N 17, 1983. 
Queremos hacer notar con esto que esta cadena dialógica sobre la que venimos insistiendo desde los inicios del texto no se sustenta ni en espacios y tiempos determinados, sino que trasciende esas dimensiones y es colocada en la escena por los mismos sujetos y casi de la misma forma.

No nos detendremos tanto en el artículo en sí, sino en la operación de sentidos que genera un párrafo en especial, que referenciamos casi textualmente:
"si la renuencia hacia la "última instancia" que practican de hecho muchos de los textos contenidos en el libro que comentamos denunciara una justa insatisfacción respecto de esa metafísica de lo infraestructural que acecha al marxismo como el felino a su presa, ¿no habrá llegado también para el pensamiento argentino de izquierda la oportunidad de reclamar el derecho al postmarxismo ${ }^{57}$ ?"58

Nos detendremos en la pregunta de Terán y sus semejanzas y diferencias con el inicio del debate en Controversia en el que Aricó se preguntaba si no habrá llegado el momento de que los marxistas argentinos acepten los riesgos de una polémica más allá de sus obtusas resistencias.

Claramente en las dos preguntas hay una intención finalista y en cierto punto teleológica, y una lectura que intuye un presente maduro para aceptar que hay que atravesar un estado en pos de llegar a otro y que de cierta forma, según expresa Terán, eso implicaría la renuncia a la "última instancia", es decir, a toda posibilidad de determinismo aunque este fuera, valga la redundancia en última instancia.

Terán altera la categoría "marxistas argentinos" de Aricó, por "pensamiento argentino de izquierda", situación que nos deja ver por lo menos dos movimientos: el primero es el pleno pasaje al plano de las ideas de lo que antes era entre otras cosas, una opción teórico-política; el segundo es la inclusión del problema de la nación en su enunciado, cabe recordar que este último movimiento apareció recurrentemente en los textos de Controversia y en otras construcciones de Terán, como por ejemplo, los estudios sobre Aníbal Ponce o José Ingenieros.

Otra diferencia, tal vez la mayor, entre las dos preguntas y entre los dos momentos, es el anuncio del derecho al postmarxismo, darle entidad a ese estado, a esa "forma teórica" parafraseando a Del Barco, sin "última instancia". Esa es la mayor operación de sentido, porque mientras que Aricó y los debates de Controversia -graficándolo en términos clásicos- se preocupan por la transición,

\footnotetext{
${ }^{57} \mathrm{El}$ resaltado es nuestro.

58 Oscar Terán, “¿Adiós a la última instancia?”, Punto de Vista, Revista de Cultura, Año VI, N 17, 1983, 47.
} 
Terán se atreve a proponer un momento diferente, en el que el desafío se encuentra en trazar las márgenes del postmarxismo.

En el número diecinueve, correspondiente a diciembre de 1983, a pocos días del triunfo de Raúl Alfonsín, José Sazbón ${ }^{59}$ interviene en este debate respondiéndole a Oscar Terán. Sazbón descompone la argumentación de manera analítica y enumera el orden con el que se estructura el texto:

1. La "última instancia" es desechable la agobian su notoriedad, su misterio, su ineficacia.

2. La "última instancia" constituye un cerco insuperable para un marxismo no metafísico.

3. Luego, quien desee eludir la metafísica ("también" el pensamiento argentino de izquierda) debe quebrar esa tradición insidiosa e instalarse del otro lado de la coupure: en el "postmarxismo". ${ }^{60}$

Pone en evidencia la existencia de debates preexistentes y la tendencia a ocultar, o por lo menos mantener en la sobra, pactos de lecturas ominosos referidos a la crisis del marxismo $\mathrm{y}$, acusa a Terán de preferir un relativismo de los descentramientos indefinidamente estancos antes que "una recaída en "esa metafísica de lo infraestructural" -es decir, la última instancia hecha sistema y opio intelectual- que, "acecha al marxismo como el felino a su presa""61.

En el número veinte de la misma publicación, Terán retoma el debate con un título nuevamente sugerente: Una polémica postergada: la crisis del marxismo ${ }^{62}$. Allí, exterioriza una serie de marcas que tendrán un impacto profundo en la concepción de Nuestros años sesentas, al poner en duda toda la tradición del marxismo y su capacidad explicativa a lo largo de su historia como tal.

Pero como nuestro interés no está puesto en el debate en sí, sino en la reconstrucción de la cadena dialógica y de qué manera las huellas de algunos eslabones trascienden en los demás, hemos decidido referenciar un párrafo completo y no dedicarnos a profundizar los argumentos que recorren el artículo. Sostiene Terán:

“... si el marxismo fue para alguno de nosotros, durante años, un modo de decir "no", un hilo con el que se tejía la tela de nuestras

\footnotetext{
59 José Sazbón, "Derecho a réplica: Una invitación al postmarxismo", Punto de Vista. Revista de Cultura, Año VI, N 19, 1983.

${ }^{60}$ Ibid., 36.

61 Ibid., 36-37.

62 Oscar Terán, “Una polémica postergada: la crisis del marxismo", Punto de Vista. Revista de Cultura, Año VII, Nº 20, 1984.
} 
rebeldías ante las injusticias sociales y un estado de cosas que nos resultaba intolerable, hoy, acosado por la práctica de Estados y partidos autoritarios que lo reclaman como su ideología oficial, y cuestionado por los funestos errores promovidos por el deseo de revolución en nuestro país, es preciso que ingrese en un arreglo de cuentas en donde nuestras responsabilidades difícilmente podrían exagerarse ${ }^{63 " 64}$.

Una contribución de Beatriz Sarlo es el cuarto artículo elegido. Intelectuales, escisión o mímesis ${ }^{65}$ es una programática político-intelectual publicada en pocas páginas. Se encuentra en el número veinticinco de la revista Punto de Vista de 1985.

En escasas páginas, Sarlo realiza una aguda re-lectura del pasado en la que opone la "acción" a la "razón crítica". Ese binarismo le permite sentenciar que, "ni en el peronismo ni en los partidos de izquierda revolucionaria se podía actuar y pensar al mismo tiempo"66, lo que marca toda una clara reinvención de la relación entre intelectuales y política.

Luego de esta lectura binaria de la realidad pasada, va a mencionar reiteradamente una figura clave: "intelectuales que protagonizaron los momentos cruciales", sobre los que va a marcar una programática precisa y contundente que puntualizaremos de manera gráfica:

- "los intelectuales que protagonizaron los momentos cruciales de los últimos años no necesariamente deben convertirse a la estética del fragmento o iniciarse en la práctica del escepticismo con la misma pasión con que se entregaron a la perspectiva revolucionaria.

- [deberían evitar] quedar petrificados en la contemplación de nuestro pasado, ya sea bajo la forma del momento revolucionario derrotado o de la equivocación monstruosa de la cual nada puede extraerse. Es decir, contemplar el pasado como lo que puede ser un futuro deseable o como el error absoluto.

- [sentir] alivio frente a esta pérdida de referentes, en la medida en que la crisis de los referentes políticos se constituye en

\footnotetext{
${ }^{63} \mathrm{El}$ resaltado es nuestro

64 Oscar Terán, "Una polémica postergada: la crisis del marxismo", Punto de Vista. Revista de Cultura. Año VII, Nº 20, 1984, 20.

65 Beatriz Sarlo, "Intelectuales: ¿escisión o mímesis?", Punto de Vista. Revista de Cultura, Año VII, $\mathrm{N}^{\circ} 25,1985$.

${ }^{66}$ Ibid., 4.
} 
condición de una mayor indeterminación de sus propias posiciones frente a lo político, para decirlo brevemente, en condición de ejercicio de su libertad.

- repensar las relaciones entre cultura, ideología y política, como relaciones gobernadas por una tensión ineliminable que es la clave de la dinámica cultural, en la medida en que la cultura y política son instancias disimétricas $\mathrm{y}$, por regla general, no homológicas. Se trataría, entonces, de pensar al intelectual como sujeto atravesado por esta tensión y no como subordinado a las legalidades de una u otra instancia, listo para sacrificar en una de ellas lo que defendería en la otra" 67.

Consideramos que la mejor manera de cerrar este apartado es con una pregunta que al menos sea, algo más que una expresión de conjeturas: ¿Podemos acaso, seguir sin ver las huellas destacadas en estos textos, como parte de las "advertencias" de Terán?

\section{IV}

El siguiente eslabón en este debate es Nuestros años sesentas. Ahora avanzaremos en una lectura del "apéndice", en esta misma clave.

Este capítulo es la reproducción de un panel que se realizó en el Club de Cultura Socialista con motivos de poner en debate a Oscar Terán y Silvia Sigal, quienes habían publicado libros sobre un objeto semejante en 1991. Punto de Vista reprodujo en su número cuarenta y dos, del año 1992, la totalidad de las presentaciones y la editorial Siglo XXI se encargó de incluirlo en esta edición definitiva.

Rescatamos de este debate dos pasajes en los que interviene Oscar Terán. El primero de ellos señalando el segundo momento de profundo cambio en su trayectoria personal, que es la incorporación a lo que Silvia Sigal llama "partido cubano"68. Allí destaca el año 1975, momento en el que descubre, de manera muy confusa que las ideologías también son mortales y que para él y no tan sólo para él "el hilo de los días se había cortado"69 y de 1976 como el año de la derrota.

Párrafos más abajo, encontramos dos afirmaciones que nuevamente reiteran su convencimiento en algunos planteos: "verifi[qué] una vez más que el

\footnotetext{
${ }^{67}$ Ibid., 4-6.

68 Oscar Terán y Silvia Sigal, “Los intelectuales frente a la política”, en Oscar Terán, Nuestros Años Sesentas. La formación de la nueva izquierda intelectual argentina, Buenos Aires, Siglo XXI Editores, 2013. 274.

${ }^{69}$ Ibid., 274-276.
} 
pensamiento siempre llega tarde"70 y "creo también que pocas veces como en esos años se pudo percibir el salvajismo de las pasiones ideológicas: un conjunto de ideas que estructuraron un conjunto de sujetos y los hicieron ser lo que fueron"71.

Sobre las dificultades en su trabajo, Terán sostiene que le interesó volver a ver lo visto, y a leer lo leído, con la enorme dificultad de que ese que ahora leía ya era otro y busca en Todorov las bases de una práctica que se encuentra en las márgenes entre la historia y la memoria. Comenta:

"un texto de Todorov me sugirió algo acerca de este problema; se refiere a tres figuras sociales que tienen una diferente relación con su objeto: el científico, que pone la mayor distancia entre su subjetividad y el objeto que considera: el político, que carece de toda distancia y aplasta sus pasiones sobre el objeto, el intelectual, que tiene que mantener una distancia con el objeto, pero como su objeto son pasiones y tragedias no puede evitar tener una relación pasional" 72 .

Hay además, otros eslabones en la cadena, en los que podemos seguir rastreando huellas. La estación Foucault ${ }^{73}$ en el número cuarenta y cinco de Punto de Vista y Pensar el pasado 74 , en el número cincuenta y ocho de la misma revista.

En este último texto se pregunta sobre la relación entre juicios, justicia e historia y continúa una reflexión de largo aliento, volviéndose sobre la relación entre los fines o los finales, en el sentido Hegeliano y sus sentidos para reinterpretar el pasado, para concluir con una afirmación sobre los setenta: "si se trata de pensar los setentas incluyendo la derrota como dato definitorio, la situación de esta reflexión es aún más compleja, porque a la debacle políticomilitar se le superpuso la crisis de la idea misma de revolución y aun del propio marxismo"75.

Y el último eslabón al que nos referiremos, es a una intervención del año 2006 en la Revista Lucha Armada: La década del setenta. La violencia de las ideas.

Allí sostiene su concepción de sujetos configurados por ideas, en este caso: concepciones con fuertes tendencias totalizadoras, cuando no integristas .Introduce el problema de las consecuencias no queridas de los actos, en efecto, para los setenta: ¿cómo pensar la responsabilidad de quienes quisieron un mundo mejor y resultaron uno de

\footnotetext{
70 Ibid., 274.

71 Ibid., 275.

72 Ibid, 277.

73 Oscar Terán, "La estación Foucault”, Punto de Vista. Revista de Cultura, Año XVI, N 45, 1993.

74 Oscar Terán, "Pensar el pasado", Punto de Vista. Revista de Cultura, Año XX, N 58, 1997.

75 Ibid., 2.
} 
los metales mortales que se fundieron sin residuo en la caldera del diablo de la política argentina? Postula la responsabilidad sobre las ideas por las que "nos dejamos atrapar" y de la interrelación compleja y a veces bizarra entre ideas y acciones humanas

\section{Consideraciones finales}

Este movimiento que se inicia con la intención de reflexionar los mundos que reiteradamente fueron creándose por las lecturas recurrentes de "Nuestros años sesentas", tuvo sus límites problemáticos cuando lo asumido como existente en esta literatura no podía ocultar la tensión que generaba otra posible interpretación del vínculo entre intelectuales de izquierda y política.

El procedimiento esencial para poner en duda nuestros mundos de sentidos, fue asumir que los mismos no son sólo nuestros, sino que allí encontramos una multiplicidad de voces y la que más sonaba era la de Oscar Terán, situación que tiene su lógica.

El primer paso, en este camino, lo dimos inspirados en la crítica de Ginzburg al abordaje que Skinner realiza de Utopía de Tomas Moro, al que cataloga como una obra de Filosofía Política. Ginzburg sostiene que ese libro es un árbol de otro bosque 76 . De ningún modo podemos afirmar lo mismo para el caso de Nuestros años sesentas, porque no tenemos las evidencias suficientes. Pero, si asegurar que esa metáfora nos sirvió para poner en dudas si ese árbol correspondía a ese bosque. Es decir, ¿ese texto que hemos leído y ha formado innumerables mundos de lectores, es un texto de historia o sólo es un texto de historia?

Desde allí, comenzamos a reflexionar si el texto que mayoritariamente había pre-figurado miradas era solamente una "historia" o como Terán sostiene: una "historia de las ideas". Y pudimos componer una argumentación que pone en consideración que es más que eso, ya que se trata de una "operación histórica" para "intervenir" en un debate sobre la crisis del marxismo, que por esa sola condición, es una "operación teórico-política" y que a su vez, el sujeto que se encarga de reconstruir esa historia exterioriza los condicionamientos de esa operación y coloca su tarea en los límites de una tarea científica y una intelectual.

En esta reflexión, reconocimos la dimensión performativa de "Nuestros años sesentas" y asumimos una tarea de "descanonización" del mismo a partir de las nociones de Bajtín de enunciado, dialogicidad y polifonía, colocando el peso en su participación en una cadena dialógica, equiparando allí la "operación histórica" con la "operación teórico-política".

76 Carlo Ginzburg, "Ninguna isla es una isla", en Historia, Antropología y Fuentes Orales. N 35. Utopía y Contrautopía, 2006, 6. 
En ese recorrido reflexivo-textual, hemos buscado las huellas presentes en los eslabones de la cadena de enunciados que se expresan en las "advertencias" y el "final" de la obra de Terán y de algún modo esos indicios nos han llevado a explorar y también encontrar, que la misma forma parte de una cadena de discusión, sólo que sus enunciados penetraron en el tiempo y generaron significaciones profundas, aunque las mismas se encuentran en un contexto limitado. De este modo, podemos traer una vez más a colación a Ginzburg y sostener que: ninguna isla es una isla.

\section{Referencias bibliográficas}

AA.VV., "Lecciones de un moderno intenso", Revista El Río Sin Orillas, Año 2, N², Octubre de 2008, 320-345

AA.VV., “Un camino intelectual: Oscar Terán, 1938-2008”. Prismas. Revista de Historia intelectual, $\mathrm{N}^{\circ} 12,2008,191-210$

AA.VV., "Aportes y debates sobre la reedición del libro de Oscar Terán: Nuestros Años Sesentas. La formación de la nueva izquierda intelectual", Revista Quinto Sol, Vol. 17, N 2, diciembre de 2013, 1-16

Acha, Omar y D’antonio, Débora, “Cartografía y perspectivas del marxismo latinoamericano", A contracorriente. Una revista de historia social y literatura latinoamericana, NC. StateUniversity, Vol. 7. N 1. Winter 2010.

Aricó, José, “Crisis del marxismo. Presentación”, Controversia, Año I, N 1, 1979

Aricó, José, “Ni cinismo ni utopía”, Controversia, Año II, Nº 9-10, 1980.

Bajtín, Mijail, Estética de la creación verbal, Siglo XXI Editores, Buenos Aires, 1998.

Carassai, Sebastian "El malestar Terán: El factum como fatum. A propósito de Nuestros años sesentas", Prismas. Revista de Historia Intelectual, N¹9, 2015, 207-213

Del Barco, Oscar, "Respuesta a Paramio y Reverte. Observaciones sobre la crisis del marxismo", Controversia, Año I, N², 1979.

Del Barco, Oscar, “Desde el fragor del mundo", Controversia, Año II, Nº 9-10, 1980

De Ípola, Emilio, “Un Legado Trunco”, Punto de Vista. Revista de Cultura, Año XX, N 58, Agosto de 1997.

Exposito, Julia, “La crisis del marxismo en una perspectiva latinoamericana. Diálogo entre el morenismo y los estudios subalternos", Revista Izquierdas, 24, julio 2015, IDEAUSACH, 108-126

Garategaray, Martina, "Democracia, intelectuales y política. Punto de Vista, Unidos y la Ciudad Futura en la transición política e ideológica de la década de los '80", Estudios, $\mathrm{N}^{\circ}$ $29,2013$. 
Ginzburg, Carlo, "Ninguna isla es una isla", Historia, Antropología y Fuentes Orales, N 35, Utopía y Contrautopía, 2006.

Ginzburg, Carlo, Mitos, emblemas e indicios, Prometeo, Rosario, 2012.

Marx, Karl, El XVIII Brumario de Luis Bonaparte, Fundación Federico Engels, Madrid, 2003.

Montaña, María Jimena, “Consideraciones en torno a la metamorfosis del intelectual latinoamericano en los años noventa", Questión. Revista especializada en Periodismo y Comunicación, Vol. 1, N 40, Octubre-diciembre 2013.

Palti, Elías José, Verdades y saberes del marxismo. Reacciones de una tradición política ante su "crisis". Buenos Aires, Fondo de Cultura Económica, 2010

Paramio, Ludolfo y Reverte, Jorge, "Razones para una contraofensiva", Controversia. Año I, N 1, 1979.

Paramio, Ludolfo y Reverte, Jorge, “Crisis del marxismo. El marxismo y el minotauro. Respuesta a Oscar del Barco", Controversia. Año II, N 5, 1980.

Ponza, Pablo, "Los sesenta-setenta: intelectuales, revolución, libros e ideas", Revista Escuela de Historia. N 6, Salta, ene-dic 2007, 137-160

Ponza, Pablo, Intelectuales y violencia política 1955-1973. Historia intelectual, discursos políticos y concepciones de la lucha armada en la Argentina de los 60-70, Córdoba, Babel Editorial, 2010.

Sarlo, Beatriz, “Intelectuales: ¿escisión o mímesis?”, Punto de Vista. Revista de Cultura, Año VII, N² 25, 1985.

Sazbón, José, "Derecho a réplica: Una invitación al postmarxismo", Punto de Vista. Revista de Cultura, Año VI, N 19, 1983.

Schmucler, Héctor, "Apuntes e interrogantes para reflexionar sobre política", Controversia, Año III, N 11-12, 1981.

Starcembaum, Marcelo, “Historia, política y responsabilidad: Óscar Terán y la autocrítica entre los intelectuales de izquierda en Argentina", Historia de las ideas, estudios de la memoria, N 51-52, Enero-junio/ Julio-diciembre de 2012.

Terán, Oscar, “De socialismos, marxismos y naciones”, Controversia, Año II, N 7, 1980

Terán, Oscar, "Algún marxismo, ciertas morales, otras muertes”, Controversia, Año III, N $14,1981$.

Terán, Oscar, “AAdiós a la última instancia?”, Punto de Vista. Revista de Cultura, Año VI, $\mathrm{N}^{\circ} 17,1983$.

Terán, Oscar, “Una polémica postergada: la crisis del marxismo”, Punto de Vista. Revista de Cultura, Año VII. N²0, 1984.

Terán, Oscar, "La estación Foucault”, Punto de Vista. Revista de Cultura, Año XVI, N 45, 1993.

Terán, Oscar, "Pensar el pasado”, Punto de Vista. Revista de Cultura, Año XX, N 58, 1997. 
Terán, Oscar, Nuestros años sesentas. La formación de la nueva izquierda intelectual argentina, Siglo XXI editores, Buenos Aires, 2013.

Terán, Oscar y Sigal, Silvia, “Los intelectuales frente a la política”, Terán, Oscar, Nuestros Años Sesentas. La formación de la nueva izquierda intelectual argentina, Siglo XXI Editores, Buenos Aires, 2013.

Thompson, Edward P., Tradición, revuelta y consciencia de clases. Estudios sobre la crisis de la sociedad preindustrial, Editorial Crítica, Barcelona, 1984.

Thompson, Edward P., "Prefacio", Thompson, Edward. P., Obra Esencial. Crítica, Barcelona. 2002.

Trotsky, León, La revolución traicionada y otros escritos, CEIP León Trotsky-Museo Casa León Trotsky-IPS, 2014.

Vezzetti, Hugo, "Los sesenta y los setenta. La historia, la conciencia histórica y lo impensable". Prismas. Revista de Historia Intelectual, N 15, 2011, 53-62

Voloshinov, Valentin, El marxismo y la filosofía del lenguaje, Alianza Editorial. Madrid. 1992. 